\title{
Natal and neonatal teeth in children
}

Keywords: neonatal teeth, palate, supernumeraries, hypoplasia, hypomineralization

\section{Introduction}

As soon as the baby is born, in most countries, the pediatrician eventually evaluates possible alterations that might be relevant. ${ }^{1}$ Some alterations of the jaws can be identified at birth, Such as cleft lip and palate. Another problem is the early appearance of teeth in the newborn. In general the first tooth of a baby appears in the oral cavity approximately at six months of age, but could take up to 16 months to appear. However, when they erupt at birth they are called natal teeth or around the first month of age are called neonatal teeth, (Figure 1) both being considered irregular conditions..$^{2-4}$

The prevalence of natal/neonatal teeth varies depending of the different re-ports, with a range of 1:800 to $1: 30000$ cases $(0.03 \%){ }^{1-4}$ The most common location is the mandibular arch (88\%) affecting one tooth but generally involves the two lower central incisors. Girls are more affected. Approximately $95 \%$ of the teeth belong to the primary dentition while $5 \%$ are supernumeraries (extra teeth), reason to take an X-ray for a correct diagnosis. ${ }^{5}$

Natal or neonatal teeth usually lack enamel maturation (hypoplasia and/or hypomineralization) and an alteration in tooth size and shape. ${ }^{1-3}$ Its color appearance is a brown-yellowish-whitish-opaque ${ }^{1}$ (Figure 1) (Figure 2). The degree of mobility is one of the main concerns for parents and dentists. If the tooth is excessively mobile, it may spontaneously exfoliate; however due to a theoretical risk of aspiration or swallowing it should be electively re-moved. However, there are no reports of deaths from this condition. ${ }^{9}$ If the tooth is not very mobile, they should remain in the mouth, where they will gain strength and quality with time. Breast feeding should not be a concern if the tooth has a slight mobility. Mother nipples are generally not affected. However, if bleeding occurs, extraction(s) could be considered. ${ }^{10-12}$

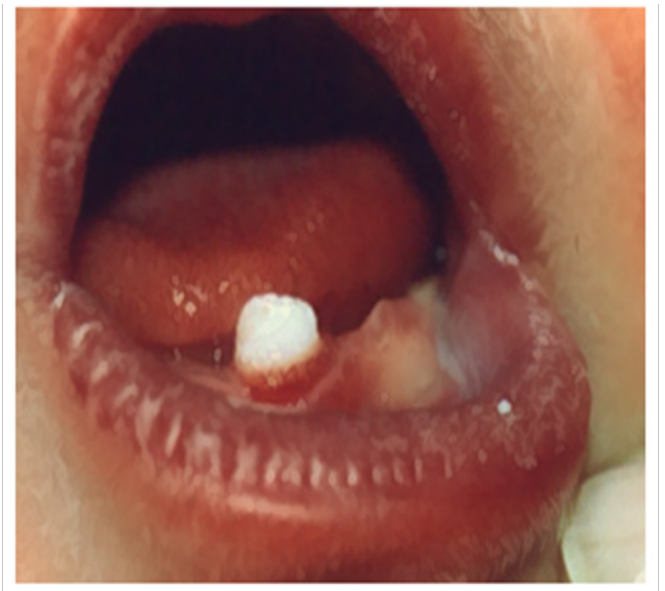

Figure I Four weeks old infant with isolated natal Teeth.

Riga-Fede is another condition which might prevent the baby from proper feeding and suckling. It consists of an ulceration of the ventral part of the tongue due to sharp edges of the natal or neonatal teeth and
Volume 3 Issue I - 2017

\author{
Eyra Rangel,' Alejandro Ramirez,' Marc \\ Saadia, ${ }^{2}$ Roberto Valencia ${ }^{2}$ \\ 'Department of Pediatric Dentistry,Autonomous University of \\ Nuevo Leon (UANL), Mexico \\ ${ }^{2}$ Department of Pediatric Dentistry, Technological University of \\ Mexico (UNITEC), Mexico
}

\section{Correspondence: Marc Saadia, Department of Pediatric Dentistry, Technological University of Mexico, Prado Sur 290, CDMX, Mexico, Tel +(52) 555540I966,}

Email drmarcsaadia@gmail.com

Received: September 12, 2017 | Published: November 03 2017

the baby thin oral mucosa ${ }^{8}$ (Figure 3 ). The treatment consists bringing the baby to the Pediatric Dentist who will smooth the edges followed by a fluorinated varnish will solve the ulceration. ${ }^{7}$ If extraction is decided, vitamin $\mathrm{K}$ should have be given to the baby to avoid bleeding. ${ }^{1,6,7.9}$ Also, care must be taken to prevent methemoglobinemia when topical anes-thetics like benzocaine and prilocaine are used. ${ }^{9}$

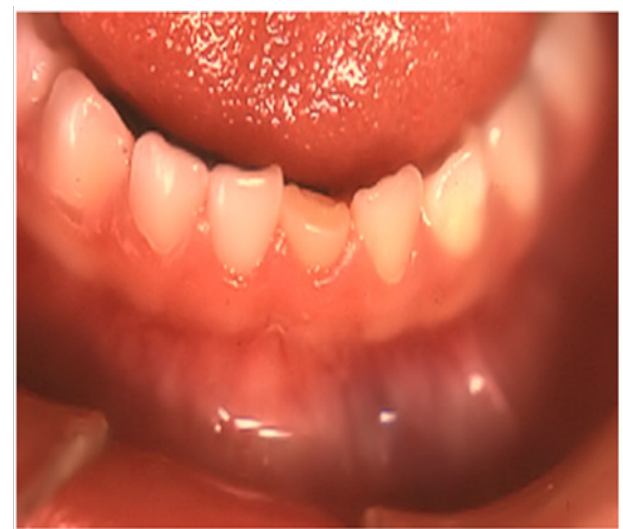

Figure 2 Defect in form color and tooth size and shape of a neonatal tooth that remained in the mouth.

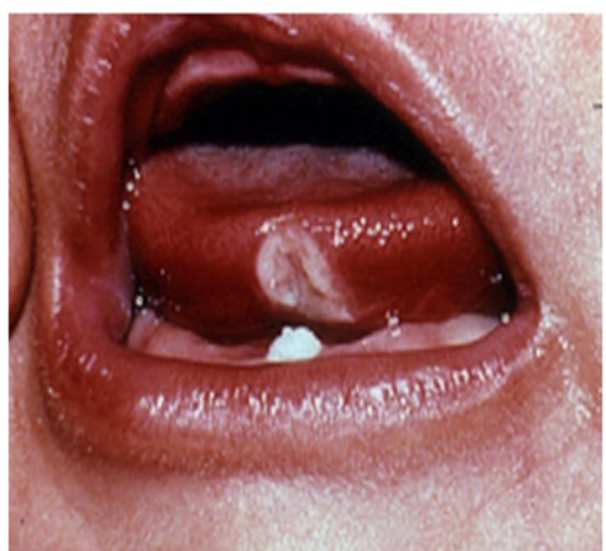

Figure 3 Riga-Fede. Note the ulceration. 


\section{Acknowledgements}

None.

\section{Conflict of interest}

Author declares that there is no conflict of interest.

\section{References}

1. Ardeshana A, Bargale S, Karri A, et al. praecox - natal teeth: a case report and review. Journal of Applied Dental and Medical Sciences. 2016;2:44-51.

2. Massler M, Savara BS. Natal and neonatal teeth: A review of 24 cases reported in the literature. J Pediatr. 1950;36(3):349-335.

3. Cunha RF, Boer FAC, Torriani DD, et al. Natal and neonatal teeth: review of theliterature. Pediatr Dent. 2001;23(2):158-162.

4. Kates GA, Needleman HL, Holmes LB. Natal and neonatal teeth: a clinical study. J Am Dent Assoc. 1984;109:441-443.
5. Bodenholf J. Natal and neonatal teeth. Dent Abstract.1960;5:485-488.

6. Basavanthappa NN, Kagathur U, Basavanthappa $\mathrm{RN}$, et al. Natal and neonatal teeth: A retrospective study of 15 cases. Eur J Dent. 2011;5(2):168-172.

7. Roopa S, Sudha VM. Natal teeth: Case report and review of literature. $J$ Oral MaxillofacPathol. 2009;13(1):41-46.

8. Slayton RL. Treatment alternatives for sublingual traumatic ulceration (Riga-Fededisease). Pediatr Dentistry. 2000;22(5):413-414.

9. Moura LF, Moura MS, Lima MD, et al. Natal and neonatal teeth: A reviewof 23 cases. Journal of Dentistry for Children. 2014;81(2):107-111.

10. De Almeida CM, Gomide MR. Prevalence of natal/neonatal teeth in cleft lip and palate infants. Cleft Palate Craniofac J. 1996;33(4):297-299.

11. Cameron A, Widmer R. Hand book of Pediatric Dentistry. Australia: Mosby-Wolfe; 1997. p. 480.

12. Baldiwala M, Nayak R. Conservative Management of Riga-Fede Disease. Journal of Dentistry for Children. 2014;81(2):103-106. 